\title{
Hybrid solar/wind/diesel water pumping system in Dubai, United Arab Emirates
}

\author{
Waleed Obaid $^{1}$, Abdul-Kadir Hamid ${ }^{2}$, Chaouki Ghenai ${ }^{3}$ \\ ${ }^{1,2}$ Electrical and Computer Engineering (ECE) Department, University of Sharjah, United Arab Emirates \\ ${ }^{3}$ Sustainable and Renewable Energy Engineering (SREE) Department, University of Sharjah, United Arab Emirates
}

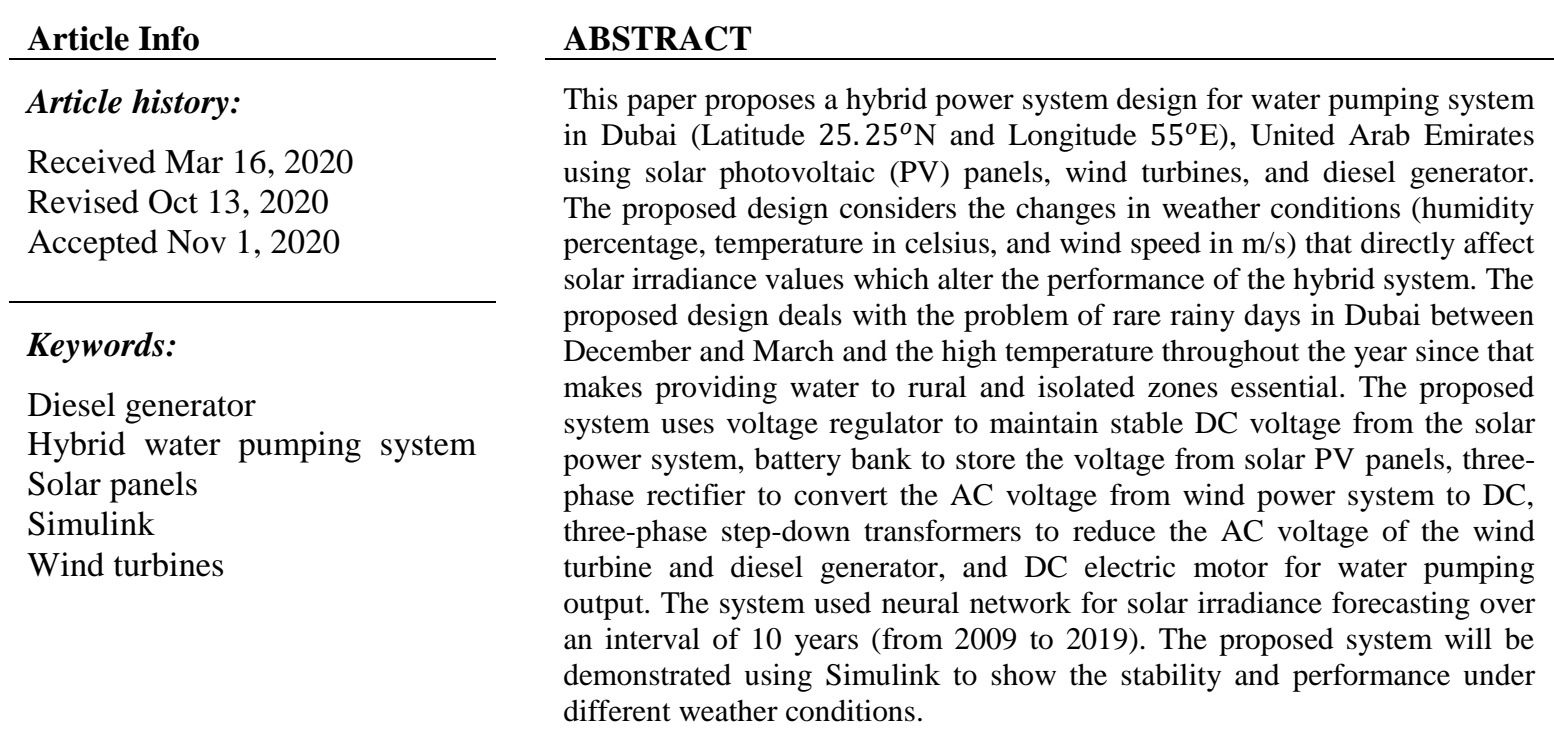

This is an open access article under the CC BY-SA license.

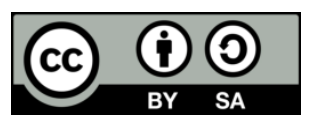

Corresponding Author:

Waleed Obaid

Electrical and Computer Engineering (ECE) Department

University of Sharjah

Sharjah, United Arab Emirates

Email: U00032590@sharjah.ac.ae

\section{INTRODUCTION}

With the continuous increase in demand of energy in all countries, solar photovoltaic (SPV) and wind based electricity generation are becoming the leading souces of non-conventional energy sources since the disadvantages of energy from only fossil sources include limited quantities and unequal geographical distribution [1]. The obtained renewable energy is promising for smart grid formation with distributed network [2].

Water is required for drinking, irrigation, livestock, and industrial purposes, therefore, water pumping is an indispensable requirement in day to day life. Attempts were made to harvest solar power for water pumping applications [3]. PV technology relies on converting solar irradiations into electrical energy, it is witnessing fast evolution and global expansion of its utilization $[4,5]$.

Dubai (Latitude 25. $25^{\circ} \mathrm{N}$ and Longitude $55^{\circ} \mathrm{E}$ ) is located in the Arabian Desert which is part of the earth's solar-belt. This location is a significant advantage since it is suitable to obtain clean and green energy that do not emit harmful substances into air to cover the increasing demand of energy annually by using 
alternative hybrid energy sources that include solar energy, fuel cell, biomass, and wind energy besides other conventional sources of energy like diesel.

Renewable and hybrid energy systems can be used in wide variety of applications in far and isolated areas as well as rural zones such as water pumping, air conditioning systems, and irrigation [6]. The main challenges that face renewable energy systems are related to weather conditions that can change any time during the day such as solar irradiance, temperature, wind speed, and humidity [7-9]. In order to solve these problems, the following additional systems have to be included in the design: battery management system, maximum power point tracking system (MPPT), and weather forecasting system in order to predict solar irradiance based on weather condition parameters [10-17]. Other solutions include using storage devices and including additional sources as part of the overall hybrid sytem [18].

Some designs were proposed for hybrid water pumping systems. A design in [19] used DC (BLDC) motor for water pump by relying on solar photovoltaic array besides battery storage for achieving a continuous water delivery regardless of the climate condition. Another design in [20] was proposed for hybrid wind turbine/solar PV water pumping systems. A wind-solar PV hybrid power system was proposed in [21]. It had battery backup to be suitable for water pumping in remote areas. A hybrid PV/FC power assisted water pumping system was proposed in [22]. They used PV system as primary electrical power source while the PEMFC was used as secondary power backup source in order to be suitable for operation in unfavorable environmental conditions. A solar photovoltaic water pumping system integrated with the singlephase distribution system was proposed in [23]. A hybrid wind/PV system for water pumping was proposed in [24]. The hybrid system was analyzed based on available wind speed records and annual solar radiation in Iraq as a case study using a small-scale hybrid wind/PV system.

The main goals of this proposed hybrid solar/wind/diesel system are: simulating the hybrid energy system which combines solar panels with solar irradiance forecasting, wind turbines, and diesel generator, analyzing the performance of the system under different weather conditions (different temperature, wind speed, and humidity), and verifying the reliability of the performance in supplying water to far and isolated areas in Dubai that have rare and limited rainy days since the increasing demand of water in these desert areas urges utilization of hybrid power systems for water pumping with high efficiency.

\section{RESEARCH METHOD}

Figure 1 shows the equivalent circuit of a solar PV panel module. The module consists of two resistors in addition to a diode and a current source. A typical solar PV panels pumping system contains DC chopper system, voltage regulator system, and DC electric motor besides the solar PV panels.

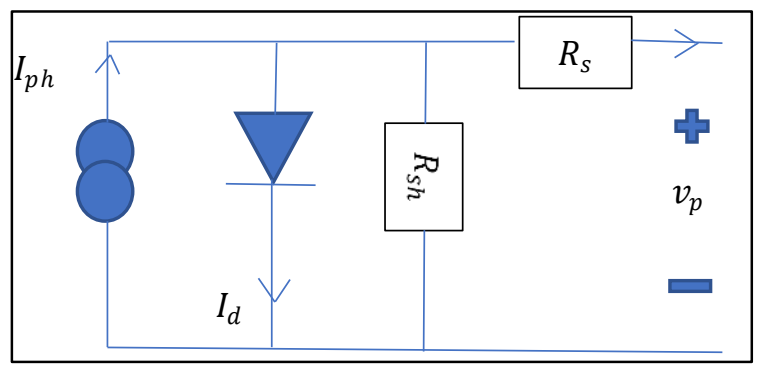

Figure 1. Solar PV cell equivalent circuit

The terminal PV module current equation is given by the expression (1):

$$
i_{P}=I_{P h}-I_{o}\left[\exp \left(\frac{v_{p}+R_{S} i_{p}}{V_{T}}\right)-1\right]-\frac{v_{P}+R_{S} i_{p}}{R_{S h}}
$$

where

$$
\begin{aligned}
& I_{o}=I_{o r}\left[\frac{T}{T_{r}}\right]^{3} \exp \left[\frac{q E_{G O}}{\gamma k}\left(\frac{1}{T_{r}}-\frac{1}{T}\right)\right] \\
& I_{p h}=\left[I_{S C R}+K_{I}\left(T-T_{r}\right)\right] \frac{\lambda}{1000} \text { and } v_{t}=\frac{N_{\gamma} K T}{q}
\end{aligned}
$$


Solar PV system has many series strings of PV modules that are linked in parallel. This assures obtaining the necessary output voltage and current to the DC motor of the pump. This nonlinear PVG characteristic can be approximated by (2):

$$
i_{g}=I_{P h g}-I_{o}\left[\exp \left(\frac{v_{g}+R_{s} i_{g}}{v_{t g}}\right)-1\right]-\frac{v_{g}+R_{S g} i_{g}}{R_{s h g}}
$$

where

$$
\begin{aligned}
& R_{s g}=R_{s}\left(N_{s} / N_{P}\right), \quad R_{s h g}=R_{s h}\left(N_{s} / N_{P}\right) \\
& I_{p h g}=N_{p} I_{p h}, I_{o g}=N_{p} I_{o} \text { and } v_{t g}=N_{s} v_{v t}
\end{aligned}
$$

A DC/DC power converter is used to alter the voltage of the PV panels by changing the duty cycle. In that block, the values of both the inductor and the capacitor are chosen in order to limit the ripple of the input and output voltages as in:

$$
\begin{aligned}
& C_{i} \frac{d v_{g}}{d t}=i_{g}-i_{L} \\
& C_{o} \frac{d v_{m}}{d t}=(1-\alpha) i_{L}-i_{m} \\
& L_{o} \frac{d i_{L}}{d t}=v_{g}-(1-\alpha) v_{m}
\end{aligned}
$$

\section{RESULTS AND DISCUSSIONS}

The proposed hybrid system is displayed in the block diagram of Figure 2 (see in Appendix). The system contains MPPT system to charge the battery bank by the solar panels, wind turbine blocks that consist of connected synchronous machine and synchronous condenser, diesel generator that is formed by diesel engine governor and synchronous machine, three-phase transformers to alter the obtained AC voltages from the wind and diesel systems, three-phase rectifier to convert the AC voltages that result from the diesel and wind systems to DC, voltage regulator to stabilize the DC voltage that comes from the solar PV panels at specific constant minimum range that is close to $12 \mathrm{~V}$ in order to suit the operation of the DC motor that is related to the pump. The values of solar irradiance were obtained using neural network blocks based on the measured average values of temperature in Celsius, wind speed in $\mathrm{m} / \mathrm{s}$, and humidity percentage in Dubai over a time span of 10 years starting from 2009 till 2019 as displayed in Figures 3 and 4.

Circuit breakers were used to switch between solar, wind, and diesel systems based on wind speed and state of charge values where the threshold values of wind speed and state of charge were $3.5 \mathrm{~m} / \mathrm{s}$ and $70 \%$ respectively [25]. The obtained voltages of the solar, wind, and diesel systems are shown in Figures 5-7. The corresponding resultant DC voltages are shown in Figure 8. Figure 9 shows the output power in $\mathrm{kW}$ of the solar panels. Figure 10 shows the speed output of the pump which was maintained stable regardless of the irradiance changes over time.

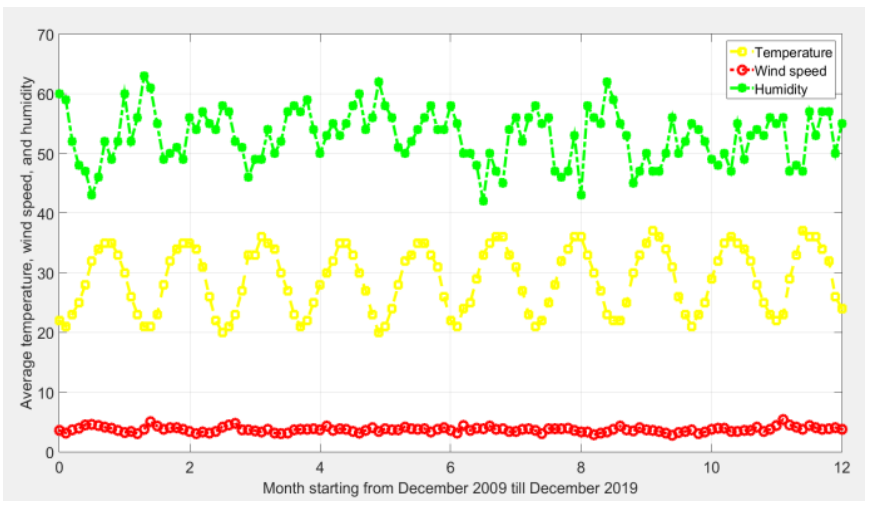

Figure 3. The average values of temperature, wind speed, and humidity over 10 years

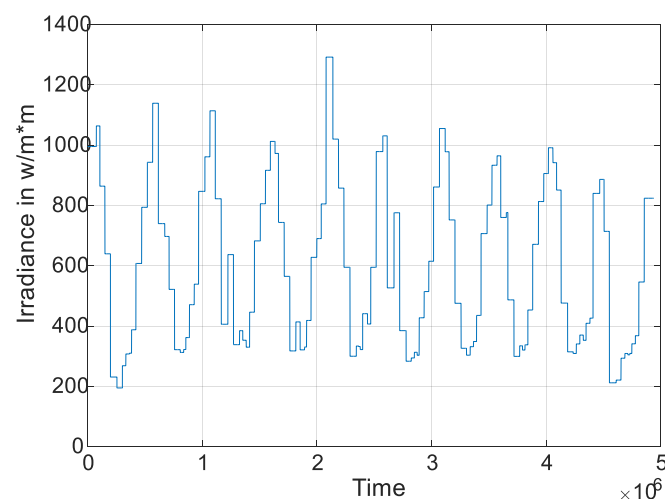

Figure 4. The obtained solar irradiance by neural network 


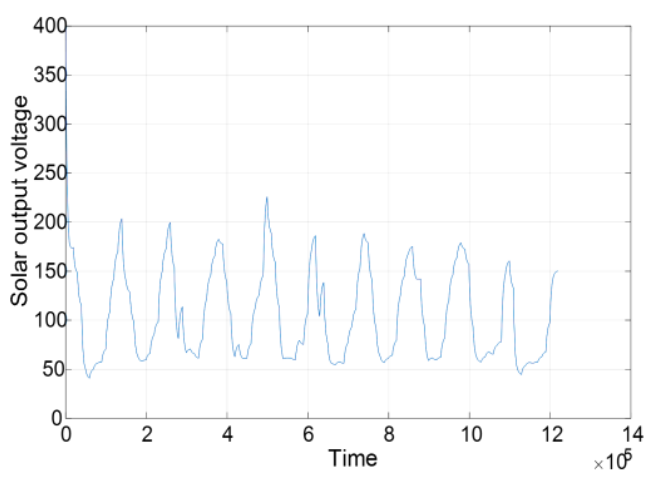

Figure 5. The obtained voltage from solar PV panels

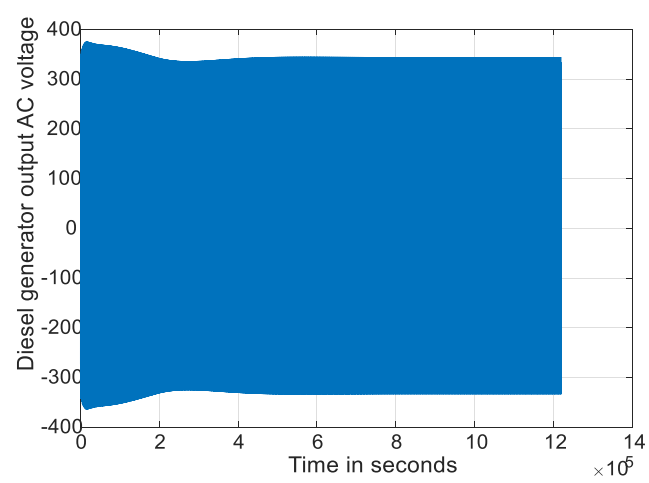

Figure 7. The output voltage from the diesel system

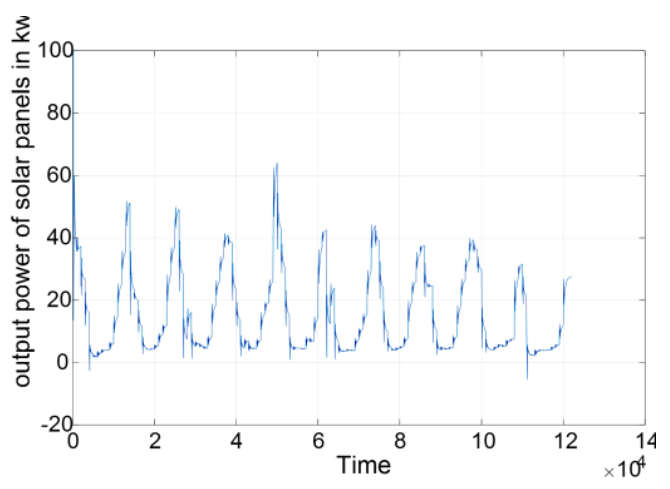

Figure 9. The output power in $\mathrm{kW}$ of the solar panels

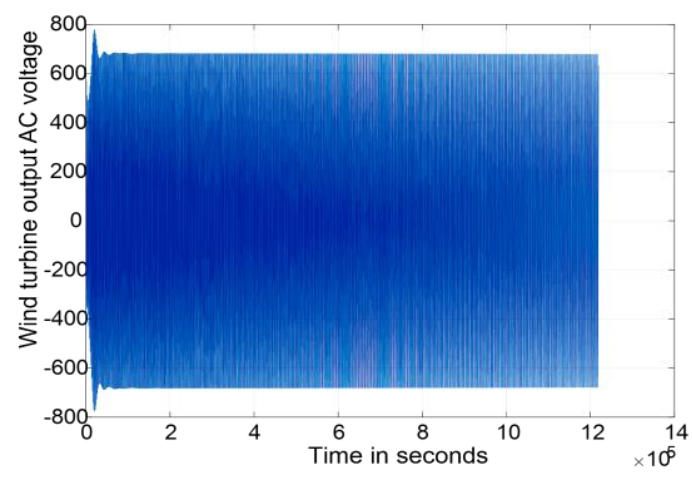

Figure 6 . The output voltage from wind turbines

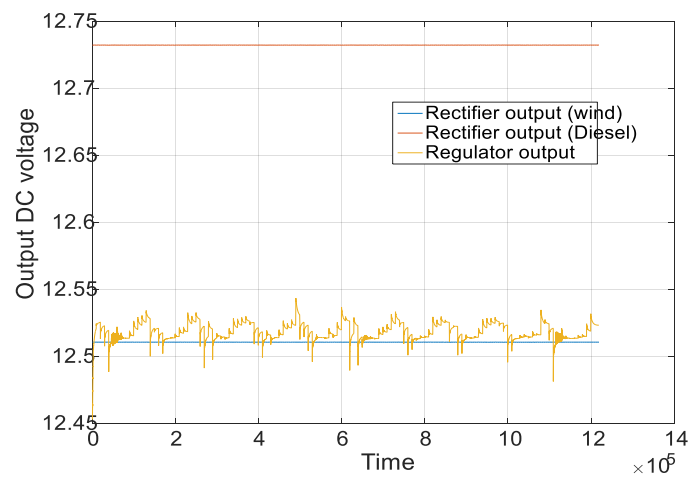

Figure 8. The obtained DC voltage

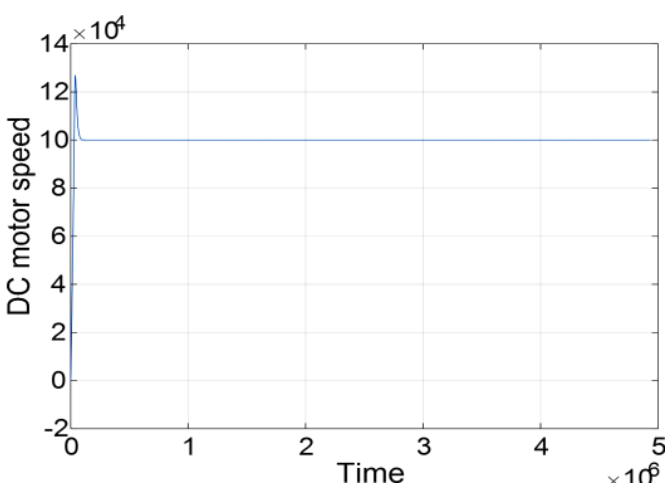

Figure 10. The speed output of the DC water pump

\section{CONCLUSION}

This paper proposed a hybrid power system design for water pumping system in Sharjah, United Arab Emirates. The proposed system combined solar photovoltaic (PV) panels and wind turbines. The system involved perturb and observe MPPT control system, three-phase transformer, battery bank, DC motor, synchronous condenser, asynchronous generator, DC-AC three-phase rectifier, and voltage regulator. The MPPT system used perturb and observe MPPT algorithm for the PV system to track the maximum power point for the photovoltaic water pumping system. The proposed system used neural network to predict the value of solar irradiance based on the average values of temperature, wind speed, and humidity over five years interval from June 2014 till June 2019. Switching between solar and wind operation was done based on wind speed using circuit breakers. The performance of the proposed system was demonstrated using MATLAB and Simulink simulations to obtain the output voltages and corresponding speed of the DC motor. The system maintained stable output voltage and speed regardless the changes in irradiance values which were affected by weather factors. 


\section{APPENDIX}
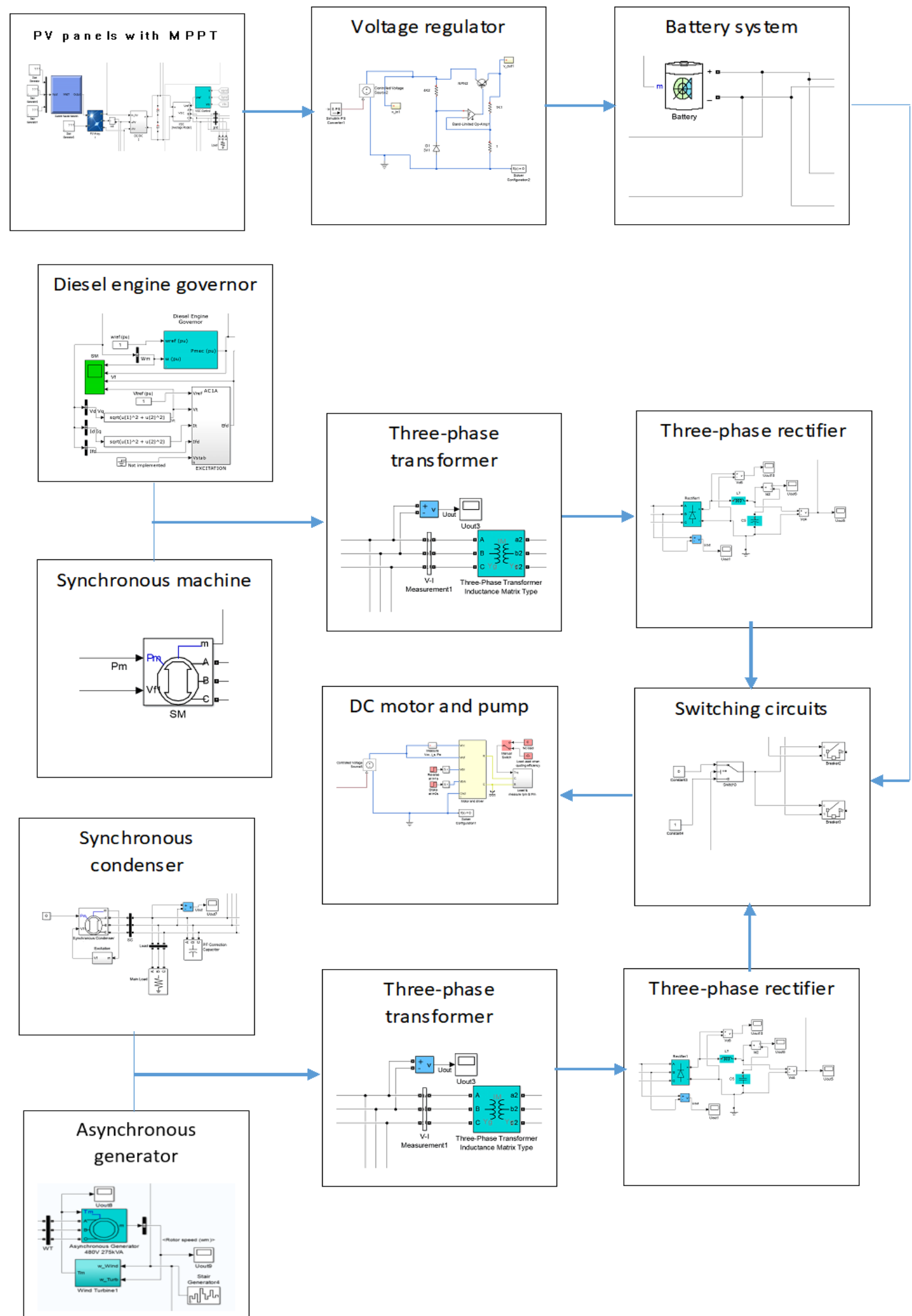

Figure 2. The proposed hybrid system

\section{ACKNOWLEDGEMENTS}

The authors wish to acknowledge the support provided by University of Sharjah, UAE. 


\section{REFERENCES}

[1] D. Mezghani, and H. Othmani, "Advanced Scalar Control with FPGA Device for Pumping Photovoltaic System," International Journal of Control and Automation, vol. 10, pp. 29-46, 2017.

[2] Sharma, Utkarsh, Bhim Singh, and Shailendra Kumar, "Intelligent Grid Interfaced Solar Water Pumping System," IET Renewable Power Generation, vol. 11, no. 5, pp. 614-624, 2016, doi:10.1049/iet-rpg.2016.0597.

[3] S. Jain, and V. Somasekhar, "An Integrated Control Algorithm for a Single Stage PV Pumping System Using an Open End Winding Induction Motor," IEEE Transaction on Industrial Electronics, vol. 63, no. 2, pp. 956-965, 2015, doi: 10.1109/TIE.2015.2480765.

[4] Allahvirdizadeh, Yousef, Mustafa Mohamadian, and Mahmoud-Reza HaghiFam, "A Comparative Study of Enery Control Strategies for a Standalone PV/WT/FC Hybrid Renewable Systems," Journal of Renewable Energy Research, vol. 7, no. 3, pp. 1463-1475, 2017.

[5] Marwa Grami, "Power Dispatch Strategy for Interconnected Microgrids Based Hybrid Renewable Energy System," Journal of Renewable Energy Research, vol. 8, no. 2, pp. 838-850, 2018.

[6] V. Salas, et al., "Analysis of control strategies for solar regulators," IEEE Int. Industrial Elec. ISIE, vol. 3, 2002.

[7] P. Rathore, et al., "Solar Power Utility Sector in India: Challenges and Opportunities," Renewable and Sustainable Energy Reviews, vol. 81, pp. 2703-2713, 2018, doi: 10.1016/j.rser.2017.06.077.

[8] M. Hayat, et al., "Solar Energy-A Look into Power Generation, Challenges, And A Solar-Powered Future," International Journal of Energy Research, vol. 43, no. 3, pp. 1049-1067, 2018, doi: 10.1002/er.4252.

[9] A. Al-Dousari, et al., "Solar and Wind Energy: Challenges and Solutions in Desert Regions," Energy, vol. 176, pp. 184-194, 2019, doi: 10.1016/j.energy.2019.03.180.

[10] J. Li, et al., "Machine Learning for Solar Irradiance Forecasting of Photovoltaic System," Renewable energy, vol. 90, pp. 542-553, 2016, doi: 10.1016/j.renene.2015.12.069.

[11] D. Verma, et al., "Maximum power point tracking (MPPT) Techniques: recapitulation in solar photovoltaic systems," Renewable and Sustainable Energy Reviews, vol 54, pp. 1018-1034, 2016, doi: 10.1016/j.rser.2015.10.068.

[12] T. Ma, and T. Shr, "Design and Hardware Implementation of a Versatile Photovoltaic Power Generating System," 2013 International Review of Electrical Engineering (IREE), vol. 8, no. 1, pp. 207-215, 2013.

[13] M. Farhat, OscarBarambones, and LassaadSbita., "A New Maximum Power Point Method Based on a Sliding Mode Approach for Solar Energy Harvesting," Applied energy, vol. 185, pp. 1185-1198, 2017, doi: 10.1016/j.apenergy.2016.03.055.

[14] K. Shah, Vijayakumar Krishnasamy, Satyanarayana Neeli, "Sliding Mode Assisted MPPT technique using Quadratic Boost Converter for Solar PV Based DC Water Pumping System," International Conference on Intelligent Computing and Control (I2C2), 2017, pp. 1-5, doi: 10.1109/I2C2.2017.8321961.

[15] A. Loukriz, Mourad Haddadi, and Sabir Messalti, "Simulation and Experimental Design of a New Advanced Variable Step Size Incremental Conductance MPPT Algorithm for PV Systems,” ISA transactions, vol. 62, pp. 30-38, 2016, doi: 10.1016/j.isatra.2015.08.006.

[16] S. Tang, et al., "An Enhanced MPPT Method Combining Fractional-Order and Fuzzy Logic Control," IEEE Journal of Photovoltaics, vol. 7, no. 2, pp. 640-650, 2017, doi: 10.1109/JPHOTOV.2017.2649600.

[17] A. Mehiri, Maamar Bettayeb, Abdul-Kadir Hamid, "Fractional Nonlinear Synergetic Control based MPPT Algorithm for PV System," Advances in Science and Engineering Technology (ASET) International Conferences, 2019, pp. 1-5, doi: 10.1109/ICASET.2019.8714527.

[18] M. Yahia, Mohamed Sélmene Ben Yahia, Hatem Allagui, Arafet Bouaicha, Abdelkader Mami., "Fuel Cell Impedance Model Parameters Optimization using a Genetic Algorithm," International Journal of Electrical and Computer Engineering, vol. 7, no. 1, pp. 184-193, 2017, doi: 10.11591/ijece.v7i1.pp196-205.

[19] R. Kumar, and B. Singh, "Solar PV-battery based Hybrid Water Pumping System using BLDC Motor Drive," IEEE 1st International Conference on Power Electronics, Intelligent Control and Energy Systems (ICPEICES), 2016, pp. 1-6, doi: 10.1109/ICPEICES.2016.7853662.

[20] B. Vick, and B. Neal, "Analysis of Off-grid Hybrid Wind Turbine/Solar PV Water Pumping Systems," Solar Energy, vol. 86, no. 5, pp. 1197-1207, 2012, doi: 10.1016/j.solener.2012.01.012.

[21] S. Rehman, and A. Sahin, "A Wind-Solar PV hybrid Power System with Battery Backup for Water Pumping in Remote Localities," International Journal of Green Energy, vol. 13, no. 11, pp. 1075-1083, 2016, doi: 10.1080/15435075.2012.729169.

[22] P. Kumar, et al., "Utilization of Energy Sources in Hybrid PV/FC Power Assisted Water Pumping System," IEEE International Conference on Computational Intelligence \& Communication Technology, 2015, pp. 548-553, doi: 10.1109/CICT.2015.81

[23] U. Sharma, Bhim Singh, and Shailendra Kumar., "Intelligent Grid Interfaced Solar Water Pumping System," IET Renewable Power Generation, vol 11, no. 5, pp. 614-624, 2016, doi: 10.1049/iet-rpg.2016.0597.

[24] A. Jadallah, and Z. Abdulqader, "Performance Analysis of a Hybrid Wind/Photovoltaic Power Generation System for Water Pumping," International Journal of Environmental Science and Technology, vol. 16, no. 9, pp. 5295-5304, 2019.

[25] S. Shokrzadeh, Mohammad Jafari Jozani; Eric Bibeau., "Wind Turbine Power Curve Modeling using Advanced Parametric and Nonparametric Methods," IEEE Transactions on Sustainable Energy, vol. 5, no. 4, pp. 1262-1269, 2014, doi: 10.1109/TSTE.2014.2345059. 